\title{
The best care anywhere
}

I remember how well everyone worked together and the patients that we cared for as if it were yesterday. Despite the decreasing coverage of events in the media, military activities were almost always occurring and resulted in a constant stream of patients, often in numbers that would overwhelm even the busiest Canadian civilian hospital.

When we received word that casualties were en route, trauma teams were assembled, surgical teams were called in, and a precise set of events was set into motion.

The deep repetitive thump of approaching helicopters signalled our casualties' arrival.

Trauma teams would receive handover from flight medics while patients

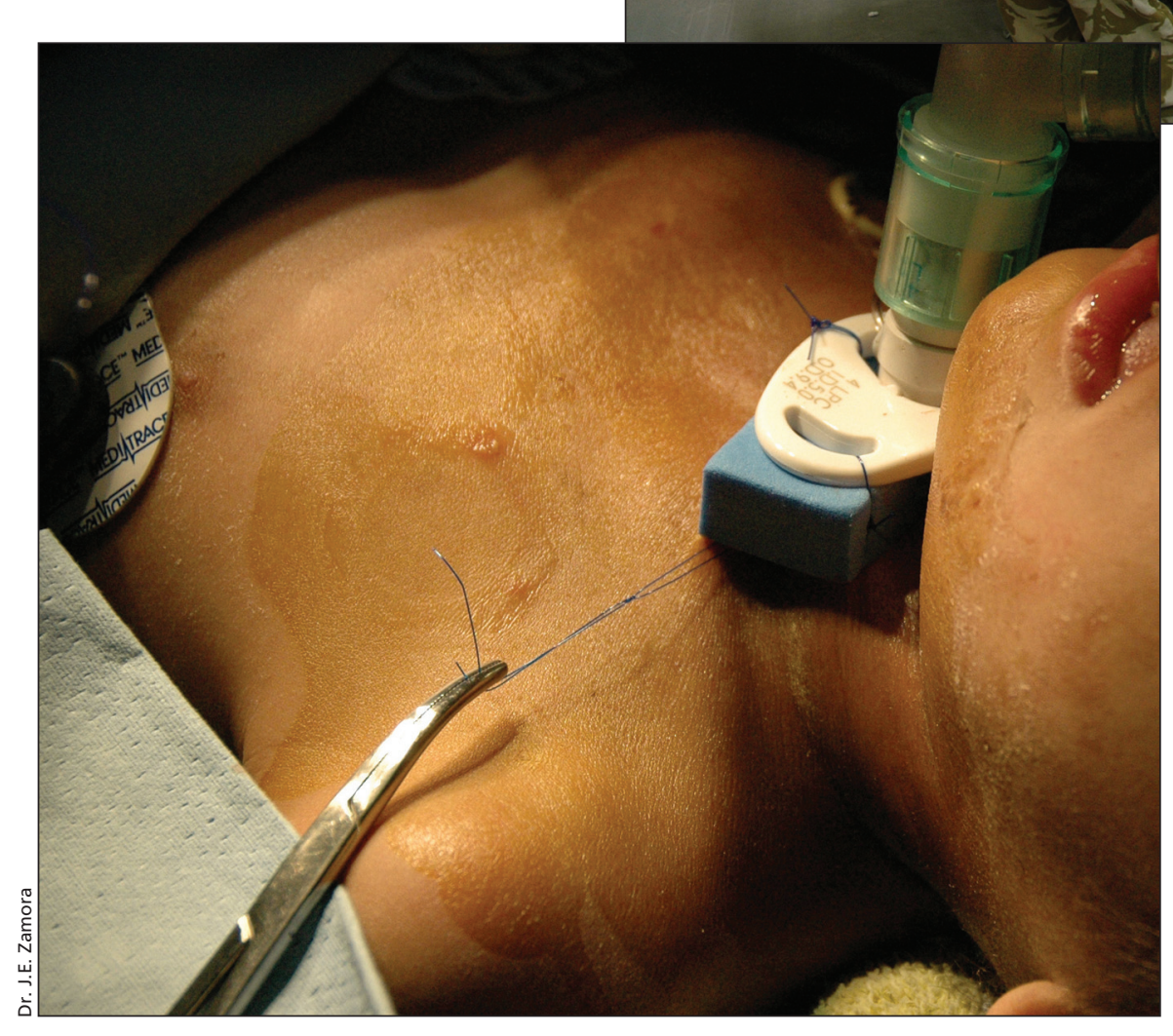

An improvised pediatric tracheotomy.



The trauma bay and medical staff at work in the multinational medical unit in Khandahar, Afghanistan.

were transported the short distance from the flight line to the hospital, searched for weapons, triaged at the door, and assigned to trauma bays. Minimal time passed from assessment and resuscitation of the most seriously injured to either diagnostic imaging in the computed tomography scanner or transfer directly into an operating room.

We were prepared for the volume and severity of battle-related injuries but pediatric casualties proved to be our most emotionally and clinically challenging patients.

Before my arrival in theatre, an Afghan boy had been brought to the hospital after a brick wall had collapsed on him. He would have certainly died if he had not been brought to us for care. 




A patient is brought to the trauma bays.

Multiple attempts to wean him from mechanical ventilation had failed. One day he was brought to the operating room for a tracheotomy.

Even our smallest tracheotomy tube was too long for our tiny patient and resulted in a mainstem intubation. Communication and cooperation between the nurses, operating-room technicians, anesthesiologists and surgeons led to a successful solution. A foam block was fashioned into a spacing device between the boy's neck and the tracheotomy tube flanges. The improvised solution worked well, and he was successfully weaned from mechanical ventilation and transferred to a hospital closer to his home. Several weeks later we learned that he was recovering well.

People often ask what working in a field hospital was like.

My response: it was rewarding, exhilarating, exhausting, challenging and occasionally terrifying.

It was almost never boring.

I was welcomed into an exceptional

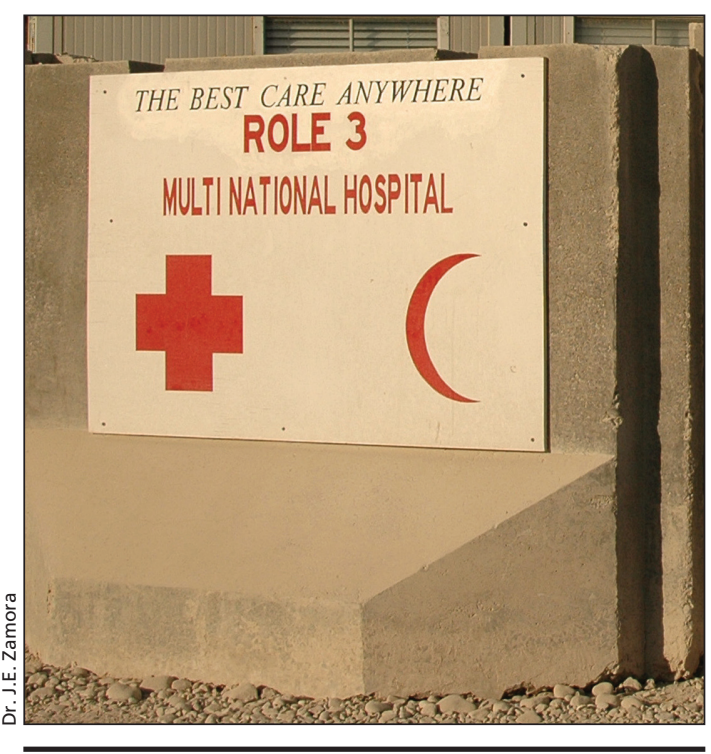

The unit has its own unofficial motto.
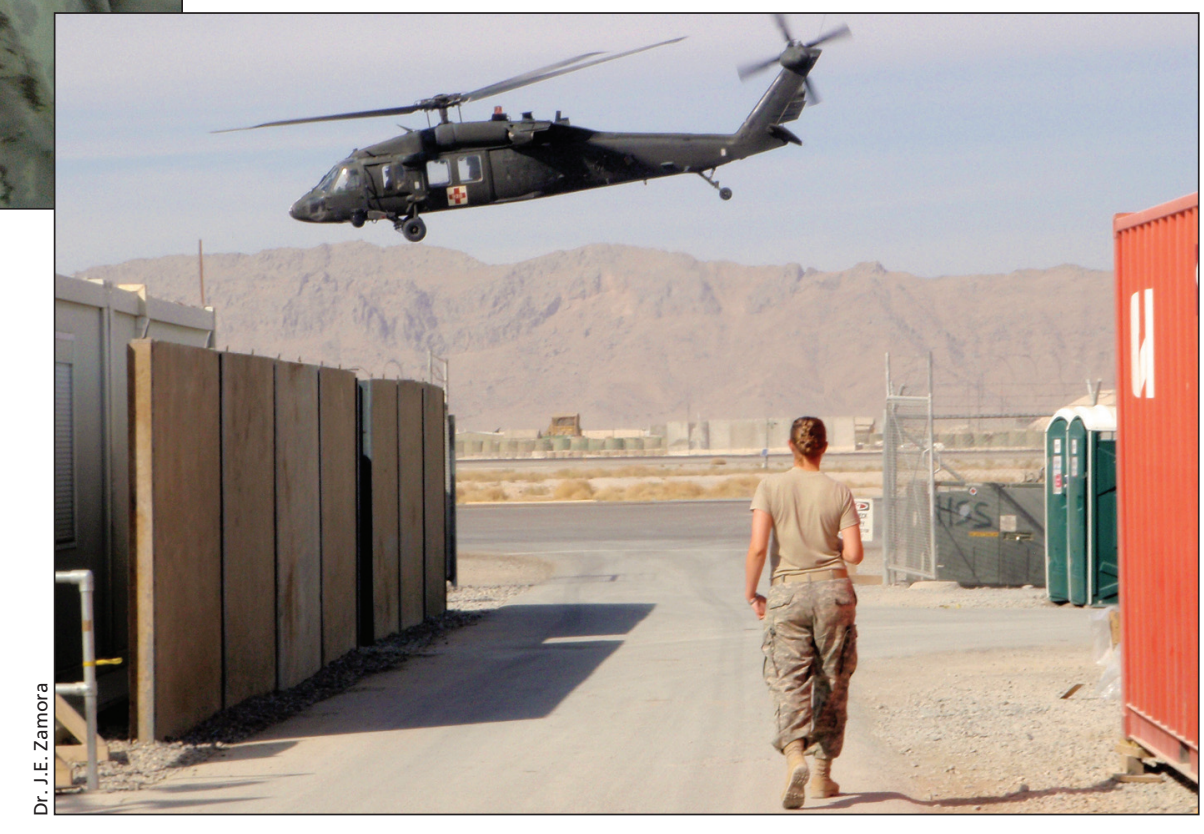

A Blackhawk helicopter delivers casualties.

team whose hard work, ingenuity, professionalism and commitment to their patients lived up to the hospital's unofficial motto.

We really did provide "The Best Care Anywhere." Every Canadian should be proud of the work being done here. - Dr. Jorge Enrique Zamora, Khandahar, Afghanistan

DOI:10.1503/cmaj.090257
CMAJ invites contributions to "Dispatches from the medical front," in which physicians and other health care providers offer eyewitness glimpses of medical frontiers, whether defined by location or intervention. Submissions, which must run a maximum 700 words, should be forwarded to: wayne .kondro@cmaj.ca. 